\title{
Differences in partnership and marital status at first birth by women's and their partners' education: evidence from Britain 1991-2012
}

\author{
Nitzan Peri-Rotem and Jacqueline Scott*
}

\begin{abstract}
Non-marital childbearing, especially within cohabitation, has become increasingly common in Britain, as in other Western countries. Nonetheless, births outside of marriage occur more frequently among individuals who are relatively disadvantaged in terms of income potential. Building upon previous research in family formation patterns, we examine differences by education and employment status in the proportion of marital and non-marital first births among British women and couples over the past two decades. In particular, we explore trends in educational differences in non-marital first births among women, and the relationship between the partners' joint educational attainment and childbearing within cohabitation or within marriage. We find that there has been a steady increase in the share of first births to cohabiting couples of all educational groups, but that there has been no significant change in the share of births to unpartnered women. Overall, our results show that the differences by educational attainment in the likelihood of having a non-marital first birth did not increase significantly during the observed period. The findings also indicate that among cohabiting couples, the male partner's education was negatively associated with childbearing, but that this relationship varied according to the woman's educational attainment.
\end{abstract}

\section{Introduction}

In recent decades, the proportion of children born outside of marriage has increased substantially across Western countries. This trend has largely been the result of an

\footnotetext{
* Nitzan Peri-Rotem (corresponding author), Department of Sociology, Philosophy and Anthropology, University of Exeter, Amory Building, Rennes Drive, Exeter EX4 4RJ, UK

Email: n.peri-rotem@exeter.ac.uk

Jacqueline Scott, Department of Sociology, University of Cambridge, UK
} 
increase in childbearing within cohabitation (Perelli-Harris et al. 2010; Wu et al. 2001). While Britain has tended to have lower levels of non-marital births than the Nordic countries, this share has increased rapidly in recent years, from $12 \%$ in 1980 to nearly half of all births currently (ONS 2015). The majority of these births are to cohabiting couples. Indeed, in recent years, just under one-third of all births in England and Wales have been to cohabiting couples (Berrington and Stone 2015).

The partnership context of childbearing in Britain is of particular interest, as the profile of non-marital childbirth in the UK is closer to the pattern observed in the United States than in the rest of Europe. Like the US, Britain has a relatively high rate of teenage pregnancy as well as a high proportion of births to single women not in a live-in partnership (Perelli-Harris et al. 2012; Sigle-Rushton 2008). Thus, at the beginning of the $2000 \mathrm{~s}, 16 \%$ of first births in the UK - but only $5 \%$ of first births in Norway and France and 3\% of first births in the Netherlands - were to a mother without a co-resident partner (Perelli-Harris et al. 2010, 786-787).

In the UK, rates of non-marital childbearing - whether to an unpartnered woman or a cohabitating couple - are disproportionately high among individuals with lower levels of educational attainment; perhaps because they have relatively poor marriage market prospects (Ermisch 2001, 2008). Moreover, these educational differences are more pronounced in the UK than in other European countries, as a comparative study on women's educational gradient of childbearing within cohabitation has shown (Perelli-Harris et al. 2010). In addition, cohabiting couples with children have been found to have lower levels of union stability in the UK than in many other European countries (Kiernan 2004; Perelli-Harris et al. 2012).

It should be noted that in the UK, the negative educational gradient of childbearing within cohabitation (unlike of unpartnered births) was less marked before the early 2000s, as the overall rates of births to cohabiting couples were relatively low (Perelli-Harris et al. 2010). Whether these differences have increased since this time remains unclear. Moreover, we know surprisingly little about the extent to which the male partner's or both partners' educational and employment characteristics are predictors of non-marital childbirth. While the vast majority of births still occur within a co-residential union, be it marriage or cohabitation; most studies on the marital context of childbearing have focused exclusively on women (Perelli-Harris and Gerber 2011; Perelli-Harris et al. 2010). Ignoring the role of men in these processes could obscure the full picture of the relationship between non-marital childbearing and the partners' educational and employment prospects for two main reasons: first, the characteristics of each partner may affect the reproductive decision-making process independently; and, second, these characteristics may interact to yield different fertility behaviours (Nitsche et al. 2015). Education in particular is likely to play an important role in childbearing within and outside of marriage, as it is linked to delayed fertility, and is a strong predictor of long-term earning capacity (Ní Bhrolcháin and Beaujouan 2012).

In the first part of this paper, we explore trends over the past two decades in the relationship between women's partnership status and educational and employment characteristics at the time of the first birth. In this analysis, we distinguish between 
married, cohabiting, and unpartnered women. In the second part of this paper, we analyse couples in a co-residential union in order to examine how both partners' educational and employment characteristics are associated with their marital status at first birth, with a particular focus on couples' joint educational characteristics.

Because of the link between unmarried parenthood and negative consequences both for mothers and children, policy-makers tend to devote considerable attention to the partnership context at birth. Not surprisingly, studies from Britain (Ermisch 2001) and the US (Wu et al. 2001) have shown that children born to cohabiting parents, and especially those born outside of a live-in partnership, are likely to spend more of their childhood in a single-parent family. Furthermore, there is a large body of evidence, mainly from the US, showing that compared to children born within marriage, children born outside of marriage are at higher risk of living in poverty, and are disadvantaged in terms of health, education, and other measures of social development (Brown 2010; Harkness et al. 2012; Kiernan and Smith 2003; McLanahan 2011).

It should be noted that there is a debate about whether a mother's partnership status at birth has a causal effect on her future social and economic outcomes, or whether these outcomes are consequences of the woman's selection into marriage or cohabitation (Goodman and Greaves 2010; Harkness et al. 2012). Previous studies have shown that in the UK, cohabiting mothers are considerably younger, are less educated, and are less likely to be in paid employment than married mothers (Berrington and Stone 2015; Kiernan et al. 2011). In addition, cohabiting couple families are more likely than married families to consist of two parents who are non-employed or in education, and to live in rented housing (Berrington and Stone 2015).

Regardless of whether the relationship between the mother's partnership status at birth and her children's outcomes is causal or is the result of selection, it is important to understand how the partners' educational and employment characteristics can shape whether the birth is to married or cohabiting parents or to a single mother, and how these trends have changed over time. In this study, we focus on first births. Because a larger share of first than of higher order births occur outside of marriage (Kiernan 2004), first births are more relevant than subsequent births for analysing educational differences in non-marital childbearing. Parental marital status at the time of childbirth matters, as it is a particularly strong indicator of future outcomes for mothers and children (Brown 2010; McLanahan 2011) - even though marital status can, of course, change from conception to birth, or after the child is born. However, previous research for the UK on marital transitions around the time of the first birth has shown that during the 1990s and the early 2000 s, more than $80 \%$ of women who had their first birth within cohabitation were still cohabiting one year after the birth (Perelli-Harris et al. 2009).

In the following, we review the theoretical background for the increase in nonmarital childbearing in Western countries, and describe the family formation trends by educational status in Britain. Based on this review, we formulate the study hypotheses. We then present a description of the data and methods used in this study, 
followed by a summary of the findings. Finally, we discuss our results, comparing them to the findings of previous literature.

\section{Background: the social context of non-marital childbearing}

Historically, childbearing outside of wedlock occurred mainly among the less advantaged segments of society, including among landless and unskilled labourers who could not afford to marry (Kiernan 2004; Laslett et al. 1980). However, the sharp increase in childbearing within cohabitation in the latter half of the $20^{\text {th }}$ century has been attributed to additional social forces, including shifts in family attitudes and the increasing economic independence of women (Bumpass 1990; Lesthaeghe 2010). According to the second demographic transition (SDT) theory, a combination of economic and social developments, including increases in education and accelerating secularisation and individualisation, have laid the groundwork for the rise in non-traditional family behaviours, such as cohabitation and extramarital births (Lesthaeghe 2010; Lesthaeghe and Surkyn 1988). Since education is one of the engines that drive normative change, the better educated are expected to be at the vanguard of these new family behaviours (Lesthaeghe and Surkyn 1988).

There is, however, little empirical support for this assumption made by proponents of the SDT. Although in some countries, such as in France, highly educated women have initiated the increase in childbearing within cohabitation; in many European countries and in the US, less educated women are more likely than their better educated peers to have a child within cohabitation (Lundberg and Pollak 2013; Perelli-Harris et al. 2010; Perelli-Harris and Gerber 2011). It has therefore been argued that the liberalisation of family norms is not sufficient for explaining the rapid increase in childbirth within cohabitation (Perelli-Harris et al. 2010), and that processes of globalisation and increasing economic uncertainty have also contributed substantially to this trend. Thus, when levels of job insecurity and of uncertainty about the future are high, cohabitation provides a reversible and less constraining alternative to marriage, especially for individuals with fewer skills and resources (Mills and Blossfeld 2005; Perelli-Harris et al. 2010).

The increased fragility of men's economic position in particular may explain the delay or the retreat from marriage and the increase in non-marital births. Oppenheimer and colleagues (Oppenheimer 2003; Oppenheimer et al. 1997) have observed that because men continue to play an important economic role in the family from both a normative and a behavioural perspective, a man with a low or unstable income would likely be seen as a less desirable marriage partner. On the other hand, uncertainty about a man's employment prospects is more tolerable in the context of cohabitation, since cohabitation is often seen as a trial stage before marriage, and the costs of breaking up a cohabiting union are lower than the costs associated with divorce (Ermisch and Francesconi 2000; Oppenheimer 2003). Empirical studies have indicated that a man's ability to fulfil the role of provider remains an important prerequisite for marriage in the United States (Gibson-Davis 
et al. 2005; Sassler et al. 2014), as well as in European countries with relatively high levels of gender egalitarianism, such as Norway and Sweden (Wiik et al. 2010). Provided the public benefits available to lone mothers (and/or the father's contributions) are sufficient, a woman might view childbearing outside of marriage as preferential to remaining single and childless (Ermisch 2008). Thus, according to Ermisch's theory of the marriage market search, childbearing outside of marriage can be seen as a rational choice that is based on the perceived costs of and gains from unmarried parenthood relative to other alternatives. For example, if a less educated woman's marriage market prospects are poor because she is likely to partner with a similarly disadvantaged man, she may prefer to have a child before marriage, rather than delaying childbearing until she can find a suitable marriage partner (Ermisch 2003, 2008).

Studies for the US have pointed to an increasing divide in family formation patterns based on education and social class. McLanahan (2004) has argued that the changes associated with the second demographic transition - such as the rise in cohabitation and divorce and the decoupling of marriage and childbearing - have followed diverging routes among the advantaged and the disadvantaged populations. Thus, while women with better opportunities typically follow a trajectory of later motherhood, or of waiting to have children until they have accumulated more resources and established a stable union; women with relatively poor prospects tend to have their first child at an earlier age, and while in a less stable union. Although cohabitation has become a socially acceptable living arrangement among all social groups, less educated women are more likely than their better educated counterparts to bear and raise children within cohabitation; whereas college educated women tend to cohabit before marriage, but to marry before having children. Thus, marriage and parenthood remain closely linked among the better educated (Lundberg and Pollak 2013). Similarly, qualitative studies from the UK have shown that the norms and the expectations of family formation differ by social group. For example, Berrington et al. (2015a) found that while levels of acceptance of non-marital childbearing have been increasing in the UK, highly educated individuals continue to prefer the more traditional sequence of getting married before having children. By contrast, less educated individuals are more likely to opt for non-marital expressions of commitment, such as buying a house and having children together. However, whether the UK is following the pattern of the increasing divergence in family formation trends observed in the US remains unclear.

\section{Education and family formation patterns in Britain}

In Britain, the relationship between education and union formation patterns has varied by birth cohort and over time. While better educated women pioneered cohabitation in Britain during the 1970s and the 1980s, less educated women eventually caught up (Ermisch 2008; Ní Bhrolcháin and Beaujouan 2013). Nonetheless, marriage rates have been continuously higher among less educated 
than better educated women, although this gap is partly due to the tendency of better educated women to delay marriage (ibid). It should, however, be noted that while highly educated women initially had higher cohabitation rates, levels of childbearing within cohabitation were lower before the 1990s than in the 2000s, with no clear educational gradient (Perelli-Harris et al. 2010).

In recent decades, the proportion of women with higher education has increased substantially; a trend that has led to a reversal of the educational gender gap among recent cohorts in the UK, as well as in many other countries (Vincent-Lancrin 2008). This change could lead to a mating squeeze; i.e. to a shortage of potential partners for highly educated women, since women tend to marry men who are at least as educated as they are (while men tend to marry women who are at most as educated as they are) (Van Bavel 2012). Alternatively, it has been suggested that an increase in gender symmetry in education and earning capacity would raise the desirability of highly educated women as marriage partners, since their contribution to the household income may be expected to be greater than in the past (Blossfeld and Müller 2002). Indeed, recent studies from Europe and other developed countries have suggested that there has been a decline in traditional marriage unions in which the man is better educated than the woman, and an increase in married couples in which the woman is better educated than the man (Esteve et al. 2012; Grow and Van Bavel 2015).

While studies from the US have suggested that highly educated women are now marrying at a higher rate than their less educated peers (Goldstein and Kenney 2001), there is so far little evidence of a reversal of the negative educational gradient of marriage in Britain; although the gap has narrowed slightly among recent cohorts (Ní Bhrolcháin and Beaujouan 2013).

In Britain, highly educated women tend to marry and have children significantly later in life than less educated women. Previous studies have shown the timing of the first birth is becoming increasingly polarised by education across birth cohorts in Britain (Berrington et al. 2015b; Ratcliffe and Smith 2006). This trend may be the result of the differential opportunity costs of early childbearing by level of education. Less educated women have fewer incentives to delay childbearing, as they are likely to remain in low-paid employment. By contrast, highly educated women, who tend to spend long periods of time in training and have increasing returns to education (Smith and Ratcliffe 2009), may be highly motivated to delay childbearing until after they have established their career.

The means-tested welfare system in the UK may have also contributed to the widening educational divide in the timing of first birth. Since family subsidies are more generous for lower than for higher earners, a highly educated woman may choose to delay childbearing until she is established in her career and can afford private child care (Rendall et al. 2009). Moreover, the provision of incometested benefits for single mothers may affect the opportunity costs of non-marital childbearing (Inanc 2015). On the other hand, in 1999, the UK government launched the Teenage Pregnancy Strategy, which aimed to reduce the conception rates of girls under age 18 (Sigle-Rushton 2008). This initiative may have contributed to the 
stabilisation in the proportion of births to non-cohabiting women around the 2000s (Berrington 2014), although rates of childbearing among cohabiting women have continued to rise (Berrington and Stone 2015).

Against this background, we wish to examine the question of whether in Britain patterns of childbearing outside of marriage have become increasingly polarised by education over the past 20 years. We also intend to investigate the relationship between both partners' educational and employment status and the likelihood of entering parenthood within cohabitation or marriage.

Differences between highly and less educated women in their martial priorities, and in their views about the acceptability of childbearing outside of marriage, may be expected to lead to a steeper increase in non-marital births among women with low or moderate levels of education. Therefore, our first hypothesis is that the likelihood of having a first birth outside of marriage has increased the most among women with low and moderate levels of education. Since the proportion of non-cohabiting women who are entering motherhood has levelled off in recent years (Berrington 2014), we expect to observe an increasing divergence in births to cohabiting women by level of education.

Theoretical explanations for the rise in the share of first births within cohabitation have assigned a particularly high degree of importance to the male partner's economic prospects, based on the assumption that less educated men are seen as less attractive marriage partners (Oppenheimer 2003; Oppenheimer et al. 1997). Thus, the second hypothesis postulates a negative relationship between the male partner's education and having a first birth within cohabitation. Men's unemployment or inactivity in the labour force is a proxy for economic uncertainty, and is expected to have a detrimental effect on the transition to marriage. Hence, our third hypothesis asserts that a woman is more likely to have a first birth while cohabiting if her male partner is not in paid employment.

Since both partners' expectations and resources are likely to influence couples' decisions about the timing of marriage and the first birth (Ermisch 2008), we expect to find that the link between male education and family formation is more pronounced in couples in which the woman has neither the highest (a college degree or higher) nor the lowest educational attainment level (less than a high school diploma). Thus, we expect to find that the role of the male partner's education is more pronounced among moderately educated women than among women with a high or a low educational level. This is because we assume that a highly educated woman is less influenced by her partner's education in making decisions about the timing of first birth, since the opportunity costs of early childbirth for such a woman remain high even when she is partnered with a less educated man. Conversely, we also assume that for a less educated woman, the opportunity costs of early childbearing are low, regardless of her partner's education. Thus, our fourth hypothesis contends that the negative relationship between the man's education and having a first birth within cohabitation (rather than within marriage) will be strongest among couples in which the woman is moderately educated. 


\section{Data and methods}

\subsection{Data}

The data for this study are drawn from the British Household Panel Survey (BHPS), which was conducted from 1991 to 2009 (University of Essex, Institute for Social and Economic Research 2010); and from the UK Longitudinal Household Survey "Understanding Society" (UKHLS, 2010-2014) (University of Essex, Institute for Social and Economic Research 2015), which has been following the original sample of the BHPS starting with its second wave in 2010. Thus, the survey covers the years 1991 through 2013. ${ }^{1}$ The BHPS is designed as an annual survey of each member (aged 16 or older) of a nationally representative sample of over 5000 households, and thus includes a total of more than 10,000 individual interviews. The same individuals are interviewed in successive waves, and if these individuals split off from one of the original households, all adult members of these new households are also interviewed. The children in each household are added to the pool of original sample members (OSMs) when they turn 16. Other entrants to the sample occur when an OSM moves into a household with one or more new people, or when a person moves in with an OSM. These new entrants, known as temporary sample members (TSMs), are interviewed in subsequent years as long as they continue to live in the same household as the OSM (Taylor et al. 2010).

The following rules mimic the demographic processes by which the population is reproduced, including birth and deaths, partnership formations and dissolutions, and emigration (Buck and McFall 2011). The one exception is immigration, as migrants who entered the UK subsequent to BHPS Wave 1 are not represented in our sample. This issue could bias population estimates for fertility (Lynn 2011). Another issue is attrition, which is of particular concern given the relatively high drop-out rates among the younger members of the BHPS sample as they were followed up in UKHLS study (Lynn et al. 2012).

In the current study, we analyse a subsample of women (either original or temporary sample members) at their main reproductive ages of 17-45 and, where applicable, their male partners. In order to examine the extent to which our sample of women are representative of the population of women aged 17-45 in Britain, we compared our sample to corresponding population estimates from the Office of National Statistics for the entire period of the survey (ONS 2016). ${ }^{2}$ Figure A.1 in the appendix shows that the age structure of the women aged 17-45 from the BHPS sample resembles the age structure of all British women in the same age groups

\footnotetext{
1 Since the data collection for the most recent (fifth) wave of the UKHLS was carried out throughout 2013 (and part of 2014), the number of births reported for that year is relatively low. Thus, the main analysis includes only the years 1991-2012.

2 Since our analysis is of retrospective childbearing events, we did not use the BHPS weights that are calculated for the prospective survey.
} 
across the different periods of the surveys. The differences between the BHPS data and the population estimates in the proportion of women in each age group do not exceed two percentage points, and there is no systematic over- or underestimation of the groups' sizes. Therefore, in terms of age distribution (17-45), our sample is broadly representative of the British population of women.

The BHPS and UKHLS surveys include rich information on socioeconomic variables, including various educational attainment and employment indicators. In addition, the data include both historical and subsequent panel records of the time of each childbirth (year and month), as well as of the year and the month of the start and the end of each cohabitation or marriage. ${ }^{3}$ The exact date of marriage was missing for a small proportion (about 4\%) of the sample in the UKHLS, which includes TSMs and those who had not been interviewed in the last wave of the BHPS. For these cases, we assumed that the marriage took place at the date of the survey wave at which the respondent's status changed to married in the UKHLS. Since there are relatively few of these cases in our sample, we do not expect this issue to cause any serious bias.

In order to test the validity of the data on the relationship status at birth, we compared our survey data to the birth registration data for England and Wales in 1991-2012. Although our study includes all British women (i.e. those living in England, Wales, and Scotland) aged 17-45 and refers to first births only, in order to maximise the comparability of our data with the birth register data, we used all birth orders for women aged 20-45 in England and Wales. ${ }^{4}$ The comparison of trends in births to married, cohabiting, and unpartnered women in England and Wales is presented in Figure A.2 in the appendix. The overall trends (1991-2012) in the relationship status at birth are similar in the BHPS estimates and in the ONS birth register data: i.e. both datasets show a decline in the proportion of births within marriage and an increase in the share of births within cohabitation and, to a lesser extent, outside of a live-in partnership. The largest deviation is observed in the years 2008-2009. This is likely due to a temporary interruption in the follow-up during the transition from the original BHPS to the UKHLS (Lynn et al. 2012). As the length of time between interviews varied from 16 to 27 months (instead of the normal 12 months) during this transition period, the estimates for partnership status at the time of birth may have been less accurate. However, apart from this deviation, the overall trends in births by partnership status in our sample fit the data from the birth register quite well.

The longitudinal design of the survey is particularly useful for the purposes of the current study, as it allows us to use lagged employment status (including educational enrolment), thereby minimising the risk of reverse causality. In addition,

\footnotetext{
3 Civil partnerships are treated as marriages. However, same-sex partnerships are not included in our study due to the small sample size.

4 Since the data for all women under the age of 20 are compiled together in the birth register, we only compared the data for women aged 20 and above.
} 
information on the timing of union formation and births is collected annually, which reduces potential memory bias. However, this survey also has some disadvantages, with the main one being the lack of information on partners who do not live in the same house as the respondent. Therefore, our analyses of couples' socioeconomic profiles and the partnership context at first birth are limited to co-residential partners. ${ }^{5}$

\subsection{Analytic strategy}

Since the partnership context at first birth is closely related to marriage probabilities, we first analyse the trends in the proportion of men and women aged 35-44 who have ever been in a union (either cohabitation or marriage), and the proportion who have ever been married by education and time period. Next, we create an event history file of women aged 17-45 during the years 1991 to 2012 based on records of the timing of their first birth and their partnership histories. We distinguish between three types of partnership statuses: married, cohabiting, and unpartnered. This third category includes women who have never been married, as well as women who are separated, divorced, or widowed. This approach allows us to track changes in the proportion of first births occurring in each of these contexts by level of education among women who had their first birth during this period.

Following the analytical approach in Perelli-Harris and Gerber (2011), we estimate monthly rates of first births within marriage, cohabitation, or outside of a live-in partnership (unpartnered). The monthly birth rate is defined as the number of first births of each type divided by the number of women at risk of having a first birth at the beginning of the month. We analyse these three types of birth rates as competing risks in a discrete-time hazard model. This model is estimated using a multinomial logistic regression (MLR), and is formulated as follows:

$$
h_{i t}(m)=\frac{\exp \left(\sum x_{i j t} \beta_{j m}\right)}{\sum_{m=1}^{M} \exp \left(\sum x_{i j t} \beta_{j m}\right)},
$$

where $h_{i t}(m)$ denotes the hazard that respondent $i$ will experience event $m$ in month $t$. Overall, there are four possible events $(M=4)$ : an unpartnered birth, a cohabiting birth, a marital birth, and no birth in month $t$. The $x_{i j t}$ represents the respondent's values on a set of $j$ time-varying covariates in month $t$. The $\beta_{j m}$ are parameters that are estimated from the data using maximum likelihood, whereby a separate parameter vector is estimated for each type of event $m$. The model is identified by setting all the elements in one such vector (the reference category) to zero. The MLR model is first estimated with "no birth" as the reference category in order to estimate the educational differences in the likelihood of having a first birth in each of the

\footnotetext{
5 For similar reasons, the analysis does not include married couples who were not living in the same household (living apart together).
} 
three partnership types. However, since this model may reflect differences by level of education in the likelihood of having a first birth in general, we run an additional model in which we use marital birth as the reference category, which allows us to assess differences by level of education in the likelihood of having a birth while unpartnered or cohabiting rather than while married. In addition, we test for an interaction between education and time period in order to examine the changes over time in the relationship between educational attainment and the partnership context in which the first birth occurs. We use a similar competing risks model to estimate the differences by level of education in couples' marital status at the first birth. However, since this model is restricted to cohabiting and married partners, there are only three possible outcomes: a birth while cohabiting, a marital birth, and no birth.

The parameter estimates of the competing risks models can only refer to the relative odds of having a first birth within a specific partnership status in relation to the baseline category (e.g., within cohabitation versus within marriage). Therefore, after fitting each of the models, we calculated the average predicted probabilities of having a first birth within marriage and within cohabitation (as well as outside of a live-in partnership in the model for women) for each educational group in our sample. This approach enables us to compare the actual probabilities of having a first birth in a given partnership status by level of education.

\subsection{Measures}

Education - This is a time-varying covariate measured by the highest level of education achieved in a given year. We identified three categories of educational attainment: low (lower secondary qualifications or less), medium (upper secondary qualifications), and high (see the appendix for a more detailed description of the educational categories and the comparability of the educational measures in the BHPS and the UKHLS). For the couples' model, we decided to use a combined education variable for both partners that initially included nine categories $(3 \times 3)$. However, since there were only a few couples in which one of the partners was highly educated while the other partner had a low educational level, some categories were collapsed, resulting in a variable with seven categories: "both low", "woman low-man higher" (medium or high), "woman medium-man low", "both medium", "woman medium-man high", "woman high-man lower" (medium or low), and "both high".

Employment status - This variable represents the employment status in the year prior to the interview. For the vast majority of the respondents, the gap between each subsequent interview was 12 months. ${ }^{6}$ However, for some respondents, the lagged employment gap was shorter. To ensure that the status represented the economic

6 In the BHPS, the mean gap is 12 months ( $\mathrm{SD}=1.3$ ), which is the same as the mean gap in the UKHLS (SD = 1.2). 
activity prior to the time of conception, we checked for robustness using a two-wave lagged employment status. The employment status variable has four categories: employed, unemployed, inactive, and in full-time education. The employed category includes all individuals who were in paid employment or were self-employed. We also distinguish between people who were unemployed and those who were economically inactive for other reasons (including being a homemaker), since these statuses might have had different implications for childbearing. In addition, it is likely that being in full-time education reduced the risk of having a first birth for both men and women.

Age - This variable refers to the current age in a given month. We included the respondents' age and age-squared to identify non-linear relationships between age and fertility risks.

Period - We included four time periods of roughly equal length (1991-1995, 1996-2000, 2001-2005, and 2006-2012) and a sufficient number of person-months in each period in order to capture trends in the partnership context at first birth.

\section{Results}

\subsection{Bivariate associations}

Table 1 presents the sample characteristics and the first birth rates for women aged 17 to 45 who were childless at the time they were first observed in the sample in 1991-2012. These characteristics include the distribution of educational attainment, employment status, and partnership status at the time of first observation; and the total number of women-months for the period during which women were at risk of having a first birth. In addition, the monthly rate of first birth has been calculated for each variable.

The results indicate that the first birth rate was highest for low educated women (0.80), while women in the middle and the high educational groups had lower birth rates that were similar in size ( 0.51 and 0.53 , respectively). Unemployed and economically inactive women had higher first birth rates than women who had been in paid employment in the preceding year (rates of 0.81 and 0.69 compared to 0.64 , respectively). The probability of having a first birth was lowest among women in full-time education (0.1). When we compare first birth rates by partnership status, we see that married women had the highest birth rate (1.4), while cohabiting women had a lower birth rate (0.7), and unpartnered women had the lowest birth rate (0.13). No major differences are found in the first birth rates across the different time periods.

The sample characteristics and the first birth rates for couples are presented in Table 2. In general, the monthly birth rate decreased with the educational attainment of both partners, although there were some interactions in this relationship. For example, couples in which the woman was highly educated had the lowest birth 


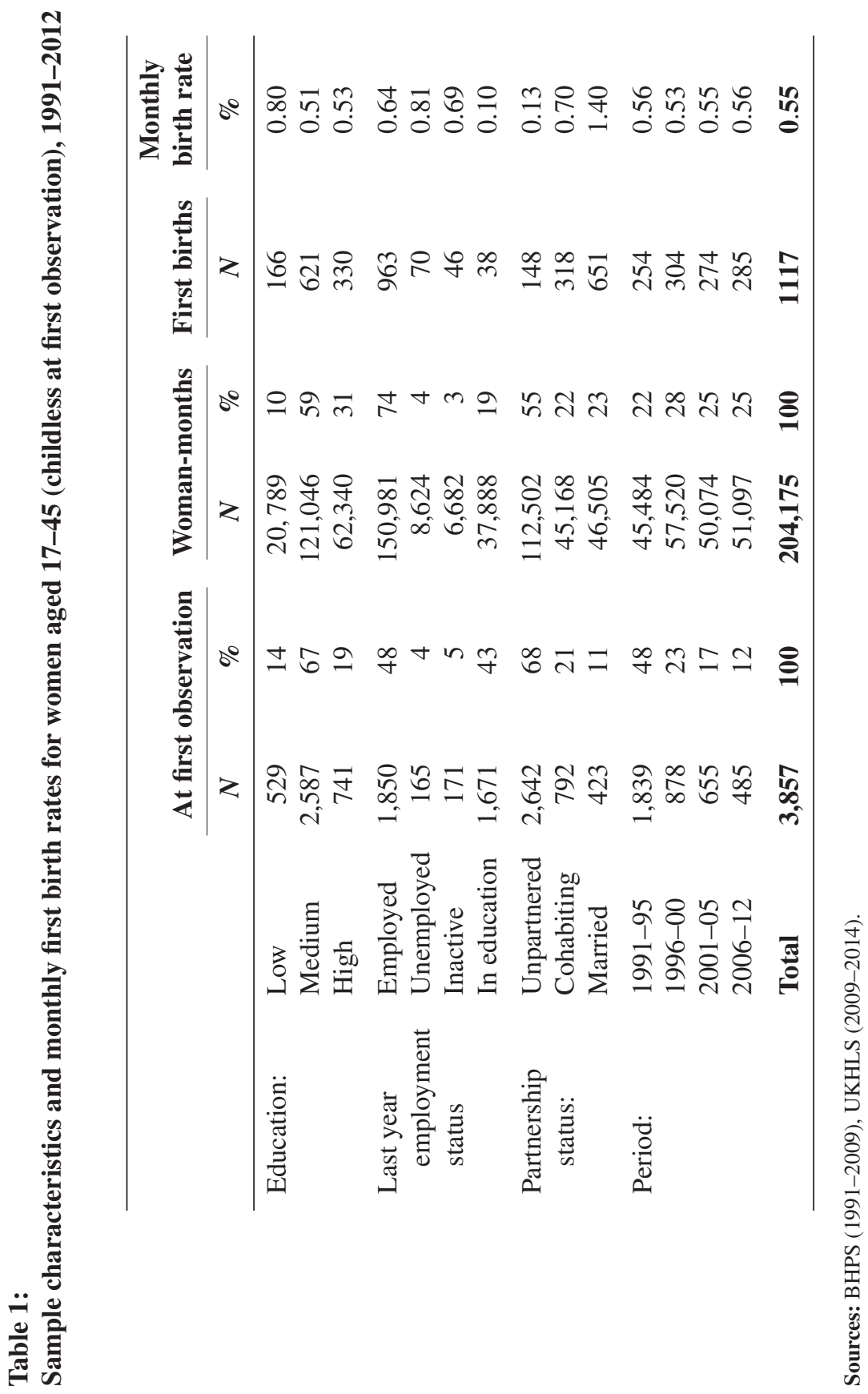




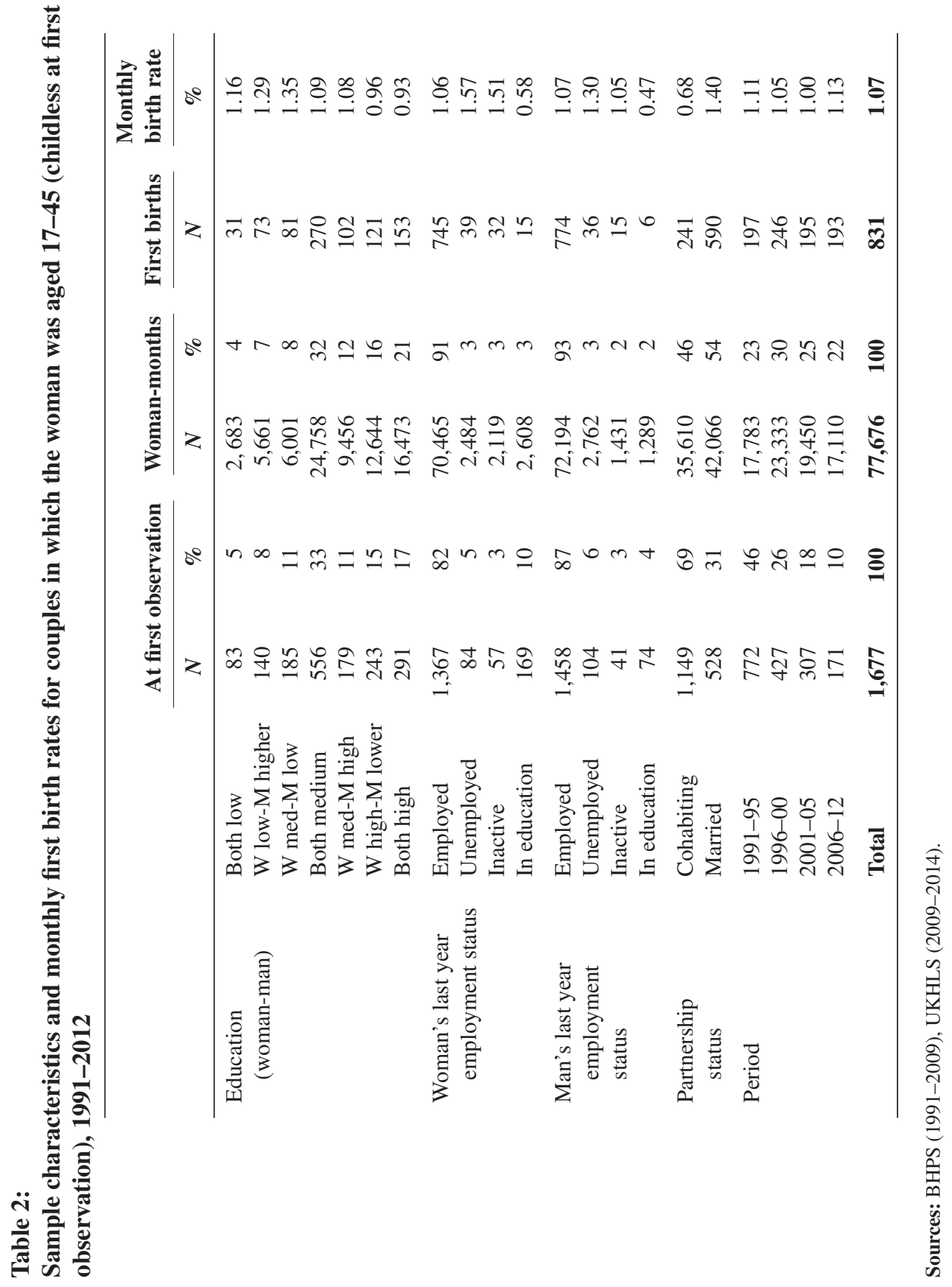


Figure 1:

Percentage of ever married/ever partnered women aged 35-44 by education and period

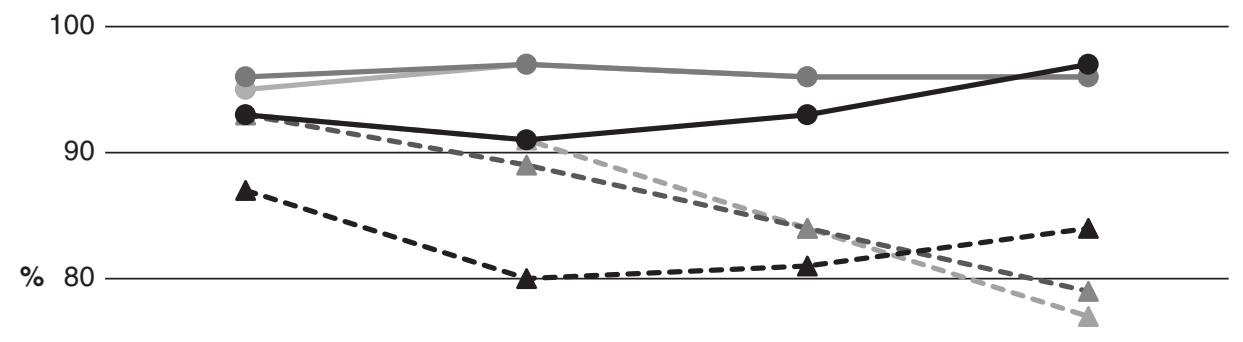

70

60

1991-95

1996-00

2001-05

2006-12

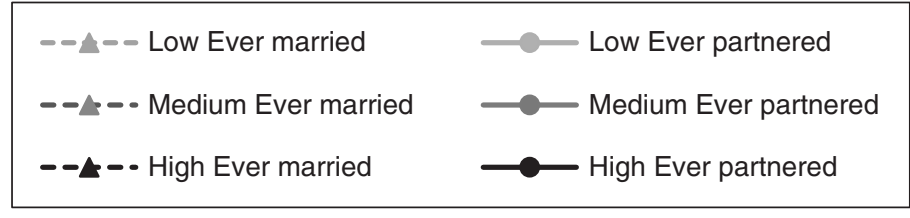

Sources: BHPS (1991-2009), UKHLS (2010-2014).

rates, regardless of the male partner's educational attainment. Among the other couples, the birth rates were higher when at least one of the partners had a low level of education.

The variation in birth rates by the woman's employment status was greater when only partnered women were included; the first birth rate was highest among unemployed (1.57) and inactive women (1.51), and was lowest among employed women (1.06). The first birth rate was also markedly lower among both women (0.58) and men (0.47) who had been enrolled in education over the preceding year. Like unemployed women, unemployed men had the highest birth rate (1.30), although no significant differences are observed between employed (1.07) and inactive (1.05) men. These rates are, however, estimated for both cohabiting and married couples, and may differ for each partnership status.

In the next section, we present the changes over time in partnership and marriage probabilities by level of education among women and men from 1991 to 2012. Figures 1 and 2 show the trends in the proportion of women and men aged 3544 in each period who had ever been in a union (either marriage or cohabitation), and the proportion who had ever been married by level of education. 
Figure 2:

Percentage of ever married/ever partnered men aged 35-44 by education and period

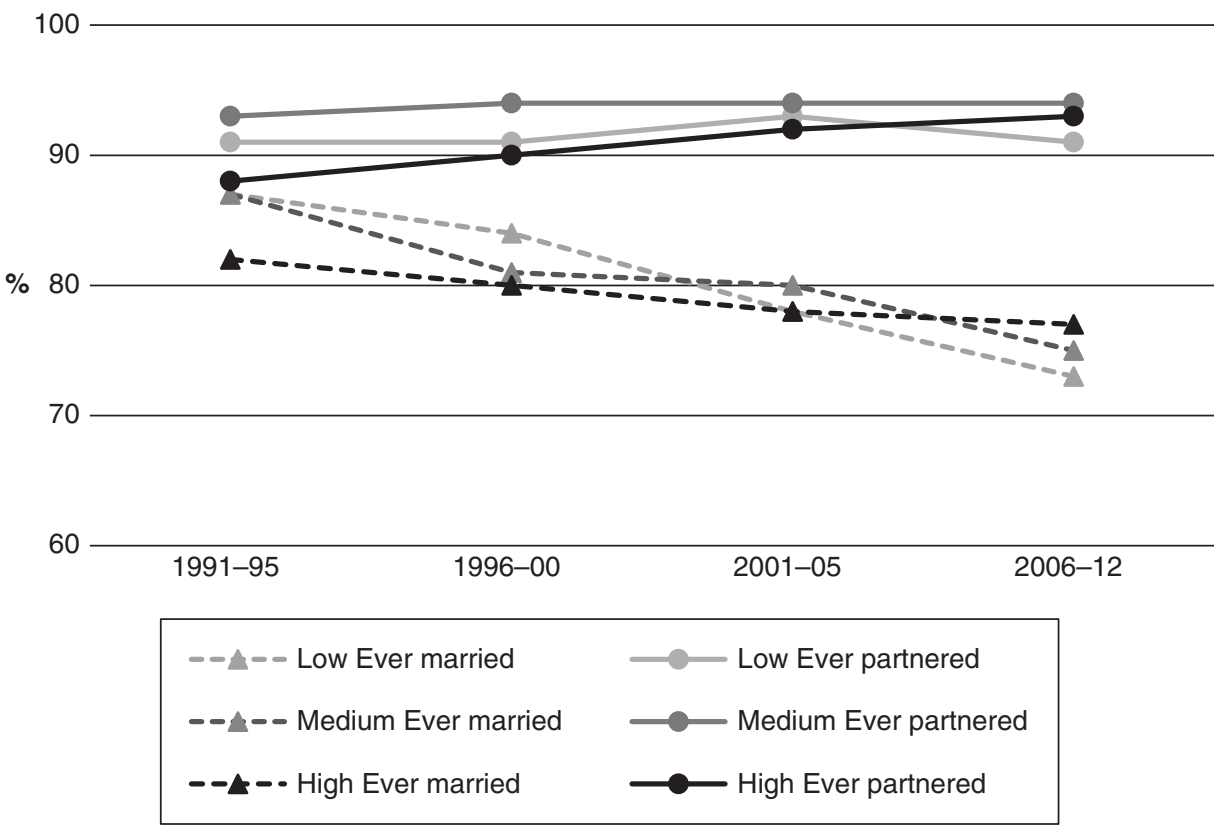

Sources: BHPS (1991-2009), UKHLS (2010-2014).

The findings on partnership probabilities among women (Figure 1) show a reversal of the previously observed educational differences in the proportion of women who had ever been married for the most recent period of 2006-12. In earlier periods, women with low or moderate levels of education had higher marriage probabilities than highly educated women. But the share of this group who had ever been married declined sharply in recent decades, from more than $90 \%$ in $1991-$ 95 to less than $80 \%$ in 2006-12. Over the same period, highly educated women became more likely to marry than in the past, and more likely to marry than their less educated peers. A similar increase is also found in the proportion of highly educated women who had ever entered any union. These trends are consistent with findings from the US indicating that the negative relationship between women's education and marriage has reversed (Goldstein and Kenney 2001). Thus, these findings fail to confirm the prediction that highly educated women would experience a "mating squeeze".

Among men (Figure 2), the educational differences in marriage and partnership probabilities were less pronounced than they were among women. However, as was the case for women, the differences by level of education in the proportion of men who had ever been married reversed in the 2006-12 period. 
In the following, we examine the trends in the partnership context at the first birth by women's education. Figure 3 presents the distribution of first births by partnership status and education across time periods. When we look at the overall trend in births by partnership type (Figure 3a), we see that until recently, the majority of first births to women in Britain were within marriage. However, in the most recent period of 2006-12, only half (49\%) of first births were to married women, while $38 \%$ of first births were to cohabiting women, and $13 \%$ of first births were to unpartnered women. While the proportion of first births within marriage declined among all women, the extent of this decline and the patterns of non-marital childbearing varied greatly across educational groups. Among the least educated women, the proportion of first births within cohabitation increased from $28 \%$ in the early 1990 s to more than one-half in the most recent period. A substantial increase in births to cohabiting women is also found among the moderately educated group, from $21 \%$ to $43 \%$ of the first births in the respective time periods. The proportion of first births to cohabiting women grew markedly over this period among highly educated women as well, from $7 \%$ to $26 \%$. However, this share was still considerably lower than it was among less educated women.

The proportion of women with a low level of education who had their first birth while unpartnered was much higher than it was among better educated women, although the share changed relatively little over the two decades studied (from $28 \%$ to $29 \%$ ). The share of women with a moderate level of education who had their first birth while unpartnered grew slightly over the study period, from $10 \%-12 \%$ in the 1990 s to $16 \%-18 \%$ after 2001 . By contrast, the proportion of highly educated women who had their first birth while unpartnered remained low over the study period, at $6 \%-7 \%$.

It therefore appears that between the early 1990s and 2012, the proportion of non-marital first births increased more among low (27\%) and moderately educated (26\%) women than among highly educated women (18\%). Thus, in the most recent period, the share of women who had their first birth while married was far higher among the women who were highly educated $(68 \%)$ than among the women with a moderate $(41 \%)$ or a low $(20 \%)$ level of education. While these estimates do not control for age and employment status, they are generally in line with the first hypothesis that the educational divide in non-marital childbearing has been increasing. Furthermore, while it appears that a relatively large proportion of highly educated women continue to wait until they are married before having their first child, it is also clear that there has been a marked increase in the share of highly educated women who have their first child while cohabiting.

The relationship between educational characteristics and the partnership context at first birth is further explored in the next section, in which we introduce a multivariate analysis of the transition to the first birth among women and couples. Table 3 presents the results of the multinomial logistic regression for the first birth by partnership status. The first three columns display the relative risk ratios for each type of birth (unpartnered, cohabiting, and marital birth) in relation to no birth, 


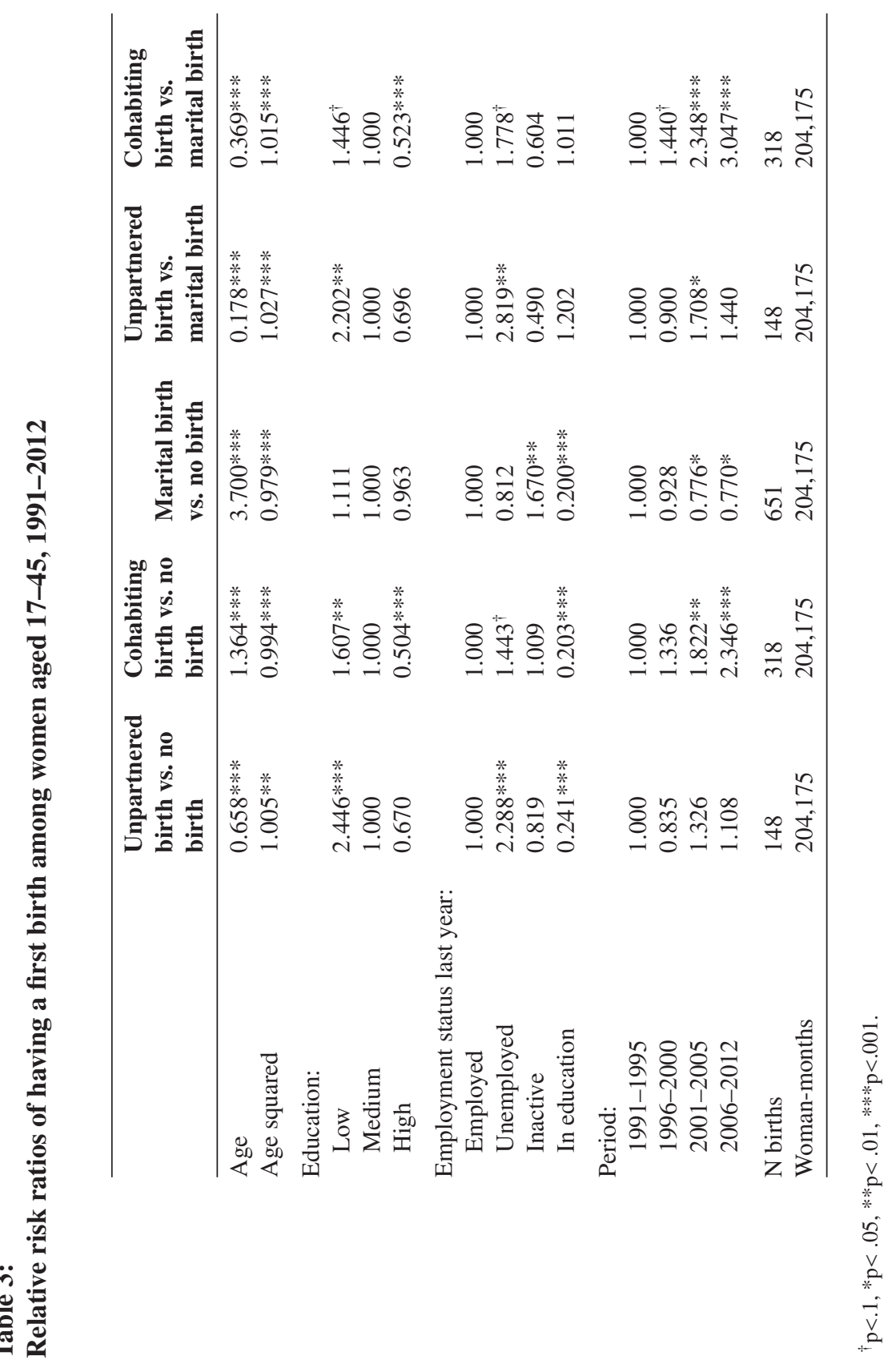


Figure 3:

First births by partnership status, education, and period for women aged 17-45

a. All women

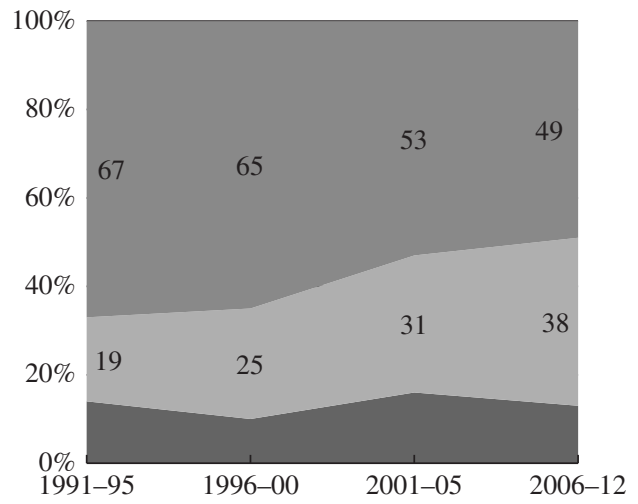

c. Medium education

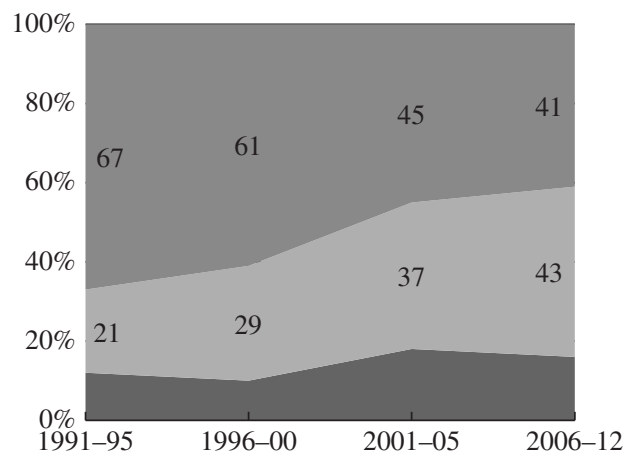

b. Low education
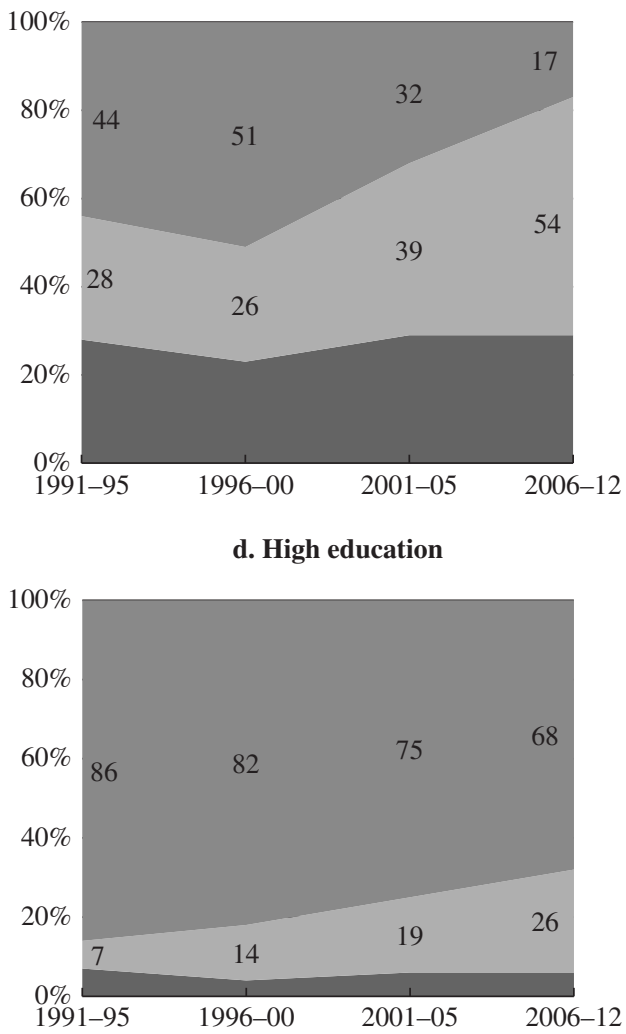

Unpartnered Cohabiting Married

Sources: BHPS (1991-2009), UKHLS (2010-2014).

and the fourth and fifth columns show the relative risk ratios for unpartnered and cohabiting births in relation to marital births.

To test explicitly for whether there was an interaction between women's education and the period, we repeated the models in Table 3 while including the educationperiod interactions (not shown here). Contrary to our first hypothesis that the likelihood of having a first birth outside of marriage increased the most among women with low or moderate levels of education, the results show that the differences by educational level in the likelihood of having a marital or a non-marital first birth did not significantly increase (or decrease) over time, but instead remained roughly the same. Since no interaction was found between education and period, 
the non-interactive model in Table 3 was considered the best fit for the data, and was therefore used for calculating the average predicted probabilities of having a first birth in each partnership status by level of education for the observed period (Figure 4).

In accordance with the descriptive findings, Table 3 and Figure 4 show that having a first birth while unpartnered was most common among women with a low level of education, and was almost equally common among highly and moderately educated women. Table 3 shows that the relative risk ratio of having an unpartnered birth as opposed to having no birth was significantly higher among women with a low than with a moderate level of education (column 1). The relative risk ratio of having an unpartnered first birth rather than a marital first birth was also higher among women with a low than with a moderate level of education (column 4).

Among cohabiting women, a strong negative educational gradient is found for first births, as less educated women were significantly more likely to have had a first birth within cohabitation than moderately educated women, while highly educated women were the least likely to have had a first birth within cohabitation (see Table 3 , column 2 and Figure 4). This gradient also appears when estimating the relative risk ratios of having a birth while cohabiting and having a marital birth (Table 3, column 5), although the differences between women with low and moderate levels of education were of marginal significance. No significant differences by education are found in the likelihood of entering motherhood within marriage (Table 3, column 3 and Figure 4). These findings imply that the negative relationship between education and the transition to a first birth was mainly the result of higher rates of non-marital births among less educated women.

A noteworthy finding is that of the change over time in the partnership context at first birth, as shown by the period dummies. No significant change over time is found in the relative risk ratios of having an unpartnered first birth and of having no birth. This result is in line with the descriptive findings displayed in Figure 3a, which show that there was no particular trend in the proportion of unpartnered births over time. On the other hand, the relative risk ratios of having a cohabiting birth increased over time in relation to both having no birth and having a marital first birth (see Table 3, columns 2 and 5).

The employment status variable in Table 3 is derived from the previous year. We chose this approach because when we included employment from the two previous waves, the number of cases was markedly reduced due to missing employment information (analysis not shown). Unsurprisingly, this robustness check confirmed our assumption that educational enrolment, rather than being in paid employment, was strongly and negatively correlated with the transition to a first birth in relation to having no birth among women in all relationship contexts (Table 3, columns $1-3)$. The results also show that being unemployed rather than being in paid work increased the relative odds of having a first birth outside of a live-in partnership in relation to having no birth or a marital birth (columns 1 and 4). This outcome makes sense given that public support for unemployed mothers is based on their partnership status and total household income (Rendall et al. 2009). Thus, it is 
Figure 4:

Predicted probabilities of having a first birth by partnership status and education for women aged 17-45, 1991-2012

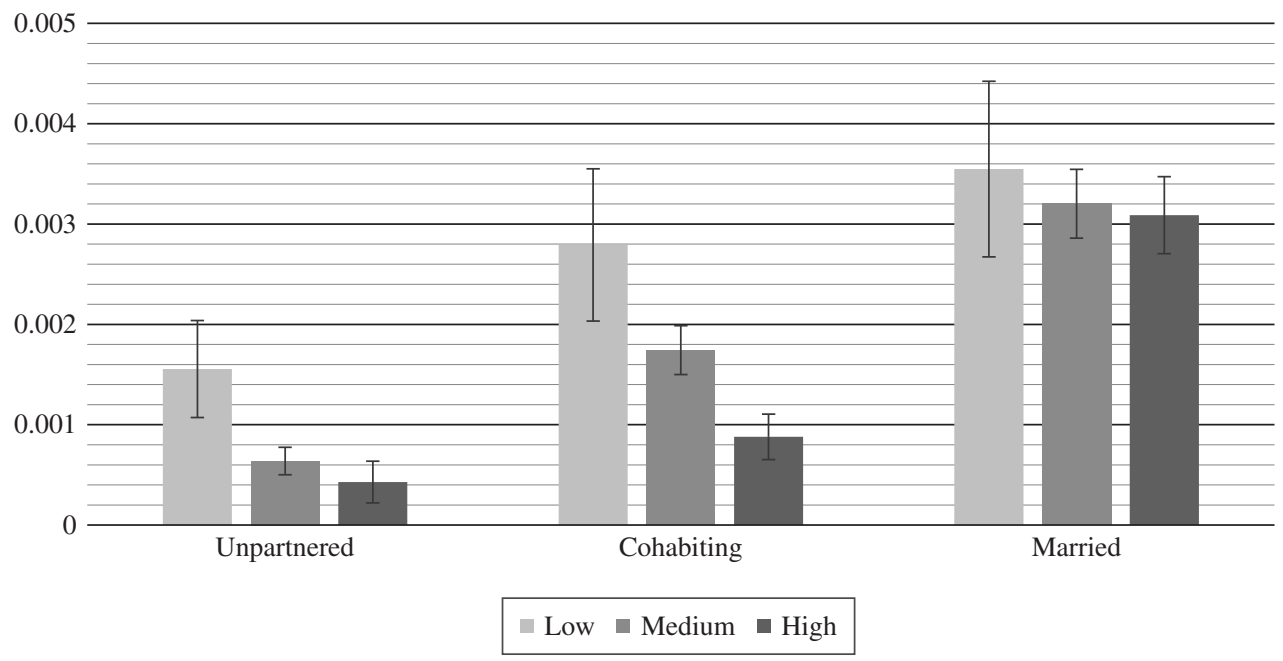

Note. Predicted probabilities are adjusted by age and employment status. Sources: BHPS (1991-2009), UKHLS (2010-2014).

possible that these women were responding to incentives to give birth outside of a live-in partnership. However, this finding must be interpreted with some caution, as it was found to be no longer significant (though still in the same direction) when the two-wave lagged employment status was used. Because there were relatively few inactive women who were in a partnership prior to having a first birth, we offer no substantive interpretation for the possible link between inactivity and marital birth versus no birth (an association that was not replicated in our robustness check).

While the probability of having a first birth within cohabitation varied greatly by women's education, it may have also changed according to the male partner's education and employment status. Table 4 presents the results of the multinomial logistic regression for having a first birth among couples. The first two columns show the relative risk ratios for having a first birth within cohabitation and within marriage (respectively), as opposed to having no birth; and the third column displays the relative risk ratios of having a cohabiting birth versus having a marital birth at the couple level.

The results for the combined education variable for couples indicate that there was a generally negative association between couples' education and the likelihood of having a first birth within cohabitation. Thus, for couples in which either the man or the woman had a low level of education (except in cases in which a highly educated woman was partnered with a less educated man), the relative risk ratios 
Table 4:

Relative risk ratios of having a first birth among couples (women aged 17-45), 1991-2012

\begin{tabular}{lccc}
\hline & $\begin{array}{c}\text { Cohabiting birth } \\
\text { vs. no birth }\end{array}$ & $\begin{array}{c}\text { Marital birth } \\
\text { vs. no birth }\end{array}$ & $\begin{array}{c}\text { Cohabiting birth } \\
\text { vs. marital birth }\end{array}$ \\
\hline Woman's age & $0.726^{* *}$ & $1.931^{* * *}$ & $0.376^{* * *}$ \\
Woman's age squared & $1.004^{*}$ & $0.989^{* * *}$ & $1.014^{* * *}$ \\
Man's age & 1.091 & $1.454^{* * *}$ & $0.750^{* *}$ \\
Man's age squared & 0.998 & $0.994^{* * *}$ & $1.004^{* *}$ \\
Education (woman-man): & & & \\
Both low & 1.250 & 1.129 & 1.106 \\
W low-M higher & $1.507^{*}$ & 0.968 & 1.556 \\
W med-M low & $1.487^{*}$ & 1.120 & 1.328 \\
Both medium & 1.000 & 1.000 & 1.000 \\
W med-M high & $0.547^{*}$ & 1.118 & $0.489^{*}$ \\
W high-M lower & $0.595^{*}$ & 0.991 & $0.600^{\dagger}$ \\
Both high & $0.464^{* *}$ & 0.952 & $0.487^{* *}$ \\
Woman's employment status last year: & & \\
Employed & 1.000 & 1.000 & 1.000 \\
Unemployed & $1.578^{\dagger}$ & 1.298 & 1.216 \\
Inactive & 1.460 & $2.624^{* * *}$ & 0.556 \\
In education & $0.493^{\dagger}$ & 0.508 & 0.971 \\
Man's employment status last year: & & \\
Employed & 1.000 & 1.000 & 1.000 \\
Unemployed & $1.645^{*}$ & 0.732 & $2.249^{*}$ \\
Inactive & $2.898^{* *}$ & $0.365^{\dagger}$ & $7.948^{* *}$ \\
In education & 1.079 & $0.284^{\dagger}$ & 3.802 \\
Period: & & & \\
1991-1995 & 1.000 & 1.000 & 1.000 \\
1996-2000 & 1.283 & 0.892 & 1.438 \\
2001-2005 & $1.645^{*}$ & $0.809^{\dagger}$ & $2.034^{* *}$ \\
2006-2012 & $2.766^{* * *}$ & $0.806^{* *}$ & $3.433^{* * *}$ \\
$N$ births & 241 & 590 & 257 \\
Couple-months & 77,676 & 77,676 & 77,676 \\
\hline
\end{tabular}

${ }^{\dagger} \mathrm{p}<.1, * \mathrm{p}<.05, * * \mathrm{p}<.01, * * * \mathrm{p}<.001$.

for having a first birth while cohabiting versus having no birth were higher than they were for moderately educated couples. The finding that this relationship was not significant for couples in which both partners were less educated may be due to the small sample size. By contrast, among couples in which the woman was highly educated, or was moderately educated but had a highly educated partner, the relative risk ratios for having a first birth while cohabiting were lower than those of the 
reference group of moderately educated partners (see column 1). As in the model for women, the likelihood of having a marital birth did not vary by couples' education (column 2). It should also be noted that as in the case for women, no significant interaction was found between couples' education and period (not shown).

When we tested the relative risk of having a cohabiting birth versus having a marital birth (column 3), we found that the relative risk ratios for having a cohabiting birth rather than a marital birth were significantly lower relative to those of the reference group only among moderately and highly educated women who were partnered with a highly educated man. Thus, these findings provide partial support for the second hypothesis that there is a negative relationship between men's education and having a first birth while cohabiting.

Couples in which the man was inactive or unemployed had higher relative odds of having a cohabiting birth than couples in which the man was employed (column 1), and this relationship appears to be stronger when the relative risk ratios of having a cohabiting birth are contrasted with those of having a marital birth (column 3). These findings support the third hypothesis, which states that when the male partner is not employed, a first birth is more likely to occur within cohabitation than within marriage. In addition, it has been shown that a man's employment status is a much stronger predictor of having a non-marital birth than a woman's employment status. This result demonstrates that traditional norms regarding the gendered division of labour and the man's role as the primary breadwinner continue to be relevant. These findings are also supported by the robustness check that used two-year lagged employment status for the male and the female partner (not shown).

In order to better understand the interaction between men's and women's education and its association with marital status at birth, we have derived the predicted probabilities for cohabiting and marital births by couples' educational composition. As we can see in Figure 5, the relationship between the man's education and the transition to a first birth within cohabitation differed by the woman's education. As was predicted by the fourth hypothesis, we found that the relationship between the man's education and having a child while cohabiting was the most pronounced for couples in which the woman was moderately educated (see bar charts 3, 4, and 5). On the other hand, among women with a high (bar charts 6 and 7) and with a low level of education (barcharts 1 and 2), the probability of having a first birth within cohabitation did not vary significantly by the level of the male partner's education. These differences could be explained by the lower opportunity costs of early childbearing for less educated women, which may have offset the importance of the man's education. Similarly, we found that the higher opportunity costs of early childbearing among highly educated women led to a delay in the first birth, regardless of partner's education.

Finally, in accordance with the regression analysis, we observed no significant differences by education in the probability of having a first birth within marriage, although the gap between the probability of having a cohabiting birth and having a marital birth varied by the educational attainment of both partners. 
Figure 5:

Predicted probabilities of having a first birth by marital status and couples' education (women aged 17-45), 1991-2012

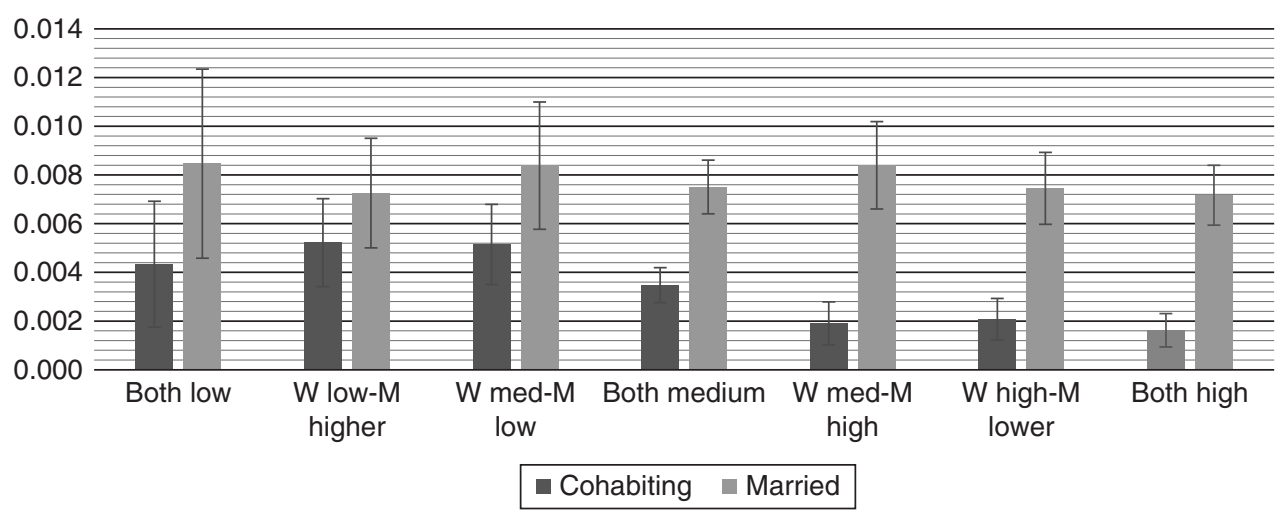

Note. Predicted probabilities are adjusted by men's and women's age and employment status. Sources: BHPS (1991-2009), UKHLS (2010-2014).

\section{Discussion}

In the present study, we explored how the partnership context at first birth varied according to the educational and employment status of women and their partners over the past two decades. The descriptive analysis of the first birth by women's partnership status from 1991 to 2012 showed that there were substantial increases in the shares of first births within cohabitation among women of all educational groups, with the levels being higher among women with a low $(54 \%)$ or a moderate $(53 \%)$ level of education than among women with a high level of education $(26 \%)$. Nevertheless, as highly educated women also became more likely over the observed period to have a first birth while cohabiting, the differences by educational level in the likelihood of having a non-marital birth did not change significantly over the study period. Meanwhile, the proportion of first births to unpartnered women remained relatively stable. Policy interventions aimed at reducing the incidence of teenage pregnancies may have played some part in this relative stability, along with the imposition of opportunity costs for non-partnered mothers through welfare-towork reforms (Brewer et al. 2012).

Thus, our first hypothesis that the educational gap in the likelihood of having a first birth outside of marriage is widening has not been confirmed. This result may reflect changes in the educational composition of women in Britain; i.e. as the proportion of women with a higher level of education increases, the highly educated group becomes more heterogeneous. This trend could have helped to suppress any further divergence by education in shares of cohabitating births. 
The increase in the share of first births within cohabitation among all educational groups may also reflect a growing acceptance of new forms of living arrangements, as suggested by the second demographic transition theory. However, this shift in family norms does not explain the continuing negative educational gradient in births within cohabitation. Therefore, it is more likely that this pattern is the result of differential earnings potential (opportunity costs); an explanation that is also supported by findings from the couples' analysis. It should be noted that cohort changes in the timing of the first birth by education may also help to explain the observed patterns. As previous studies have shown, the rise in the age at first birth across cohorts has been much more pronounced among highly educated women than among their less educated peers (Berrington et al. 2015b; Ratcliffe and Smith 2006). Since less educated women tend to have their children relatively early in the life course, they are also less likely than better educated women to be married when they have their first child. Furthermore, our findings are related to changes in partnership status at first birth across time periods. While each period is dominated by different birth cohorts, possible cohort effects on changes in family behaviours may be obscured.

After taking both men and women's characteristics into account, we found that the relative risk ratios of having a first birth within cohabitation rather than within marriage were significantly lower among medium and highly educated women who were partnered with a highly educated man than among medium educated couples. This finding indicates that the educational levels of both partners affected the likelihood of having a non-marital birth, and that this likelihood declined with men's education, as predicted by the second hypothesis. In addition, the findings support the third hypothesis, which states that a first birth is more likely to occur within cohabitation rather than within marriage when the male partner is not in paid employment. The results also indicate that the female partner's employment status was less significant than her marital status at first birth. These findings support the assumption that economic insecurity is an important determinant of non-marital childbirth, especially when it affects the male partner.

Finally, the fourth hypothesis on the interaction between men's and women's educational attainment is also supported, as the results indicate that men's educational gradient for cohabiting versus being married at the first birth was steepest among couples in which the woman was moderately educated, while there was less variation when the female partner had either a low or a high level of education. These results may reflect the differential opportunity costs of non-marital childbearing for each group; i.e. the opportunity costs associated with having a child while cohabiting may be particularly low for the least educated women and particularly high for the most educated women, regardless of the male partner's education. By contrast, moderately educated women may be more influenced by their partner's earnings capacity when making decisions about childbearing and marriage. These findings are in line with the marriage market search theory, which posits that a highly educated woman with strong marriage prospects is more likely to wait until she is married to have her first child, while a less educated woman 
who is less likely to marry a well educated man would gain less from postponing childbirth until after marriage. However, a woman with a medium level of education may have less certain marriage prospects; thus, the timing of her first birth is more likely to depend on her partner's earnings potential.

To date, there is no evidence for the UK of significant growth in the differences in rates of non-marital childbearing by level of education. However, given that marriage rates are declining more sharply among women with low and moderate educational levels than among highly educated women, it seems likely that educational differences in non-marital childbearing will remain, and that they could increase further. As McLanahan $(2004,2011)$ has argued, this pattern may reflect and preserve social class disparities, as individuals with fewer economic resources continue to have higher birth rates within cohabitation, which is a less stable union form than marriage. Given the traditional gendered division of labour that tends to arise in the wake of parenthood, union breakdown is often associated with reduced economic circumstances for both mothers and children. Thus, the persistent differences by level of education in rates of non-marital first births among women matter, not least because of their ramifications for the life chances of their children's generation.

\section{Acknowledgments}

This study was supported by the Philomathia Social Sciences Research Programme at the University of Cambridge.

\section{References}

Berrington, A. 2014. The changing demography of lone parenthood in the UK. Working Paper 48, ESRC Centre for Population Change: University of Southampton.

Berrington, A. and J. Stone 2015. Cohabitation trends and patterns in the UK. ESRC Centre for Population Change Report: University of Southampton.

http://www.cpc.ac.uk/publications/Cohabitation\%20trends\%20and\%20patterns $\% 20 \mathrm{in} \%$ 20the\%20UK.pdf, Accessed on 25 February 2016.

Berrington, A., B. Perelli-Harris and P. Trevena 2015a. Commitment and the changing sequence of cohabitation, childbearing, and marriage: Insights from qualitative research in the UK. Demographic Research 33(12): 327-362.

Berrington, A., J. Stone and E. Beaujouan 2015b. Educational differences in timing and quantum of childbearing in Britain: A study of cohorts born 1940-1969. Demographic Research 33(26): 733-764.

Blossfeld, H.-P. and R. Müller 2002. Union disruption in comparative perspective: The role of assortative partner choice and careers of couples. International Journal of Sociology 32(4): 3-35. 
Brewer, M., A. Ratcliffe and S. Smith 2012. Does welfare reform affect fertility? Evidence from the UK. Journal of Population Economics 25:245-266.

Brown, S. L. 2010. Marriage and child well-being: Research and policy perspectives. Journal of Marriage and Family 72(5): 1059-1077.

Buck, N. and S. McFall 2012. Understanding Society: Design overview. Longitudinal and Life Course Studies 3(1): 5-17.

Bumpass, L. 1990. What's happening to the family? Interactions between demographic and institutional change. Demography 27(4): 483-498.

Ermisch, J. F. 2001. Cohabitation and childbearing outside marriage in Britain. In Out of wedlock: causes and consequences of nonmarital fertility, eds L. L. Wu and B. Wolfe, 109-139. New York: Russell Sage Foundation.

Ermisch, J. F. 2003. An economic analysis of the family. Princeton: Princeton University Press.

Ermisch, J. F. 2008. The new dynamics of family formation and the explosion of childbearing outside marriage. In Women and employment: Changing lives and new challenges, eds J. Scott, S. Dex and H. Joshi, 133-155. Cheltenham: Edward Elgar.

Ermisch, J. F. and M. Francesconi 2000. Cohabitation in Great Britain: Not for long, but here to stay. Journal of the Royal Statistical Society Ser. A 163(2): 153-171.

Esteve, A., J. García-Román and I. Permanyer 2012. The gender-gap reversal in education and its effect on union formation: The end of hypergamy? Population and Development Review 38(3): 535-546.

Gibson-Davis, M. C., K. Edin and S. McLanahan 2005. High hopes but even higher expectations: The retreat from marriage among low-income couples. Journal of Marriage and the Family 67: 1301-1312.

Goldstein, J. R. and C. T. Kenney 2001. Marriage delayed or marriage foregone? New cohort forecasts of first marriage for U.S. women. American Sociological Review 66(4): 506-519.

Goodman, A. and E. Greaves 2010. Cohabitation, marriage and child outcomes, Commentary 114, London: Institute for Fiscal Studies. http://www.ifs.org.uk/publications/4823. Accessed on 28 February 2016.

Grow, A. and J. Van Bavel 2015. Assortative mating and the reversal of gender inequality in education in Europe: An Agent-Based Model. PLoS ONE 10(6): e0127806. DOI: $10.1371 /$ journal.pone.0127806.

Harkness, S., P. Gregg and L. MacMillan 2012. Poverty: the role of institutions, behaviours and culture. The Joseph Rowntree Foundation, University of Bath.

Inanc, H. 2015. Unemployment and the timing of parenthood: implications of partnership status and partner's employment. Demographic Research 32(7): 219-250.

Kiernan, K. 2004. Unmarried cohabitation and parenthood in Britain and Europe. Law and Policy 26(1): 33-55.

Kiernan, K. and K. Smith 2003. Unmarried parenthood: new insights from the Millennium Cohort Study. Population Trends 114: 26-33.

Kiernan, K., S. McLanahan, J. Holmes and M. Wright 2011. Fragile families in the US and UK. Working Paper WP 11-04- FF, Center for Research on Child Well-Being: Princeton University. 
Knies, G. ed. 2015. Understanding society - UK household longitudinal study: Wave 1-5, 2009-2014, User Manual. Colchester: University of Essex.

Laslett, P., K. Oosterveen and R. M. Smith 1980. Bastardy and its comparative history. London: Edward Arnold.

Lesthaeghe, R. 2010. The unfolding story of the Second Demographic Transition. Population and Development Review 36(2): 211-251.

Lesthaeghe, R. and J. Surkyn 1988. Cultural dynamics and economic theories of fertility change. Population and Development Review 14(1): 1-45.

Lundberg, S. and R. A. Pollak 2013. Cohabitation and the uneven retreat from marriage in the U.S., 1950-2012. Discussion Paper No. 7607, Bonn: IZA.

Lynn, P. 2011. Maintaining cross-sectional representativeness in a longitudinal general population survey. Understanding Society, Working Paper Series No 2011-04.

Lynn, P., J. Burton, O. Kamineska, G. Knies and A. Nandi 2012. An initial look at nonresponse and attrition in Understanding Society. Understanding Society, Working Paper Series, No 2012-02.

McLanahan, S. 2004. Diverging destinies: How children are faring under the second demographic transition. Demography 41(4): 607-627.

McLanahan, S. 2011. Family instability and complexity after a nonmarital birth: Outcomes for children in fragile families. In Social class and changing families in an unequal America, eds M.-J. Carlson and P. England, 108-133. Stanford: Stanford University Press.

Mills, M. and H.-P. Blossfeld 2005. Globalization, uncertainty, and the early life course: A theoretical framework. In Globalization, uncertainty and youth in society, eds H.-P. Blossfeld, E. Klijzing, M. Mills and K. Kurz, 1-24. Abingdon: Routledge.

Ní Bhrolcháin, M. and E. Beaujouan 2013. Education and cohabitation in Britain: A return to traditional patterns? Population and Development Review 39(3): 441-458.

Nitsche, N., A. Matysiak, J. Van Bavel and D. Vignoli 2015. Partners' educational pairings and fertility across Europe. Families and Societies, Working Paper Series no. 38.

Office for National Statistics 2015. Births by Parents' Characteristics, England and Wales. http://www.ons.gov.uk/peoplepopulationandcommunity/birthsdeathsandmarriages/ livebirths/datasets/birthsbyparentscharacteristics. Accessed on 28 October 2016.

Office for National Statistics 2016. Mid-year population estimates: Single year of age and sex for local authorities in the United Kingdom; estimated resident population 1991-2012. https://www.ons.gov.uk/peoplepopulationandcommunity/populationandmigration/ populationestimates/datasets/populationestimatesforukenglandandwalesscotlandandnorthernireland. Accessed on 27 October 2016.

Oppenheimer, V. K. 2003. Cohabiting and marriage during young men's career-development process. Demography 40: 127-149.

Oppenheimer, V. K., M. Kalmijn and N. Lim 1997. Men's career development and marriage timing during a period of rising inequality. Demography 34: 311-330.

Perelli-Harris, B. and T. P. Gerber 2011. Nonmarital childbearing in Russia: Second demographic transition or pattern of disadvantage? Demography 48(1): 317-342.

Perelli-Harris, B., W. Sigle-Rushton, M. Kreyenfeld, T. Lappegård, R. Keizer and C. Berghammer 2010. The educational gradient of childbearing within cohabitation in Europe. Population and Development Review 36(4): 775-801. 
Perelli-Harris, B., M. Kreyenfeld, W. Sigle-Rushton, R. Keizer, T. Lappegård, A. Jasilioniene, C. Berghammer and P. Di Giulio 2012. Changes in union status during the transition to parenthood in eleven European countries, 1970s to early 2000s. Population Studies 66(2): 167-182.

Perelli-Harris, B., M. Kreyenfeld, W. Sigle-Rushton, R. Keizer, T. Lappegård, A. Jasilioniene, C. Berghammer, P. Di Giulio and K. Koeppen 2009. The increase in fertility in cohabitation across Europe: Examining the intersection between union status and childbearing. Rostock, MPIDR Working Paper WP-2009-021.

Ratcliffe, A. and S. Smith 2006. Fertility and women's education in the UK: a cohort analysis. Working Paper No. 07/165, Centre for Market and Public Organisation: University of Bristol.

Rendall, M. S., O. Ekert-Jaffé, H. Joshi, K. Lynch and R. Mougin 2009. Universal versus economically polarized change in age at first birth: a French-British comparison. Population and Development Review 35(1): 89-115.

Sassler, S., S. Roy and E. Stasny 2014. Men's economic status and marital transitions of fragile families. Demographic Research 30(3): 71-109.

Sigle-Rushton, W. 2008. England and Wales: Stable fertility and pronounced social status differences. Demographic Research 19: 455-502.

Smith, S. and A. Ratcliffe 2009. Women's education and childbearing: A growing divide. In Fertility, living arrangements, care and mobility: Understanding population trends $V .1$, eds J. Stillwell, E. Coast and D. Kneale, 41-58. Dordrecht: Springer.

Taylor, M. F., J. Brice, N. Buck and E. Prentice-Lane 2010. British Household Panel Survey user manual, Volume A: Introduction, technical report and appendices. Colchester: University of Essex.

University of Essex. Institute for Social and Economic Research. 2010. British Household Panel Survey: Waves 1-18, 1991-2009. [data collection]. 7th Edition. UK Data Service, SN: 5151, DOI: 10.5255/UKDA-SN-5151-1.

University of Essex. Institute for Social and Economic Research, NatCen Social Research. 2015. Understanding Society: Waves 1-5, 2009-2014: Special Licence Access. [data collection]. 6th Edition. UK Data Service, SN: 6931, DOI: 10.5255/UKDA-SN-6931-5.

Van Bavel, J. 2012. The reversal of gender inequality in education, union formation and fertility in Europe. Vienna Yearbook of Population Research 10: 127-154.

Vincent-Lancrin, S. 2008. The reversal of gender inequalities in higher education: An ongoing trend. In OECD higher education to 2030. Vol. 1, 265-298. Demography. Paris: OECD.

Wiik, K. A., E. Bernhardt and T. Noack 2010. Love or money? Marriage intentions among young cohabitors in Norway and Sweden. Acta Sociologica 53(3): 269-287.

Wu, L. L., L. Bumpass and K. Musick 2001. Historical and life course trajectories of nonmarital childbearing. In Out of wedlock: Causes and consequences of nonmarital fertility, eds L. L. Wu and B. Wolfe, 3-48. New York: Russell Sage Foundation. 


\section{Appendix}

\section{Comparability of educational attainment in the BHPS and the UKHLS}

The main variables used to measure the level of education in the UKHLS do not perfectly align with the educational measures of the BHPS (Knies 2015). For example, the UKHLS survey does not distinguish between different numbers of qualifications for GCSEs or A-Levels. However, a high level of comparability between the two surveys can be achieved by collapsing some of the original education categories in the BHPS. Thus, the following classification is used:

Low education (lower secondary qualifications) - includes CSE Grades 2-5, O-Level grades D-E, GCSE grades D-G, Scottish SCE Ordinary Grade bands D-E or 4-5, Scottish Standard Grade levels 4-7, and no qualifications.

Figure A.1:

Age structure distribution of women aged 17-45 by period in Britain - comparison of the BHPS original sample with the ONS vital registration data
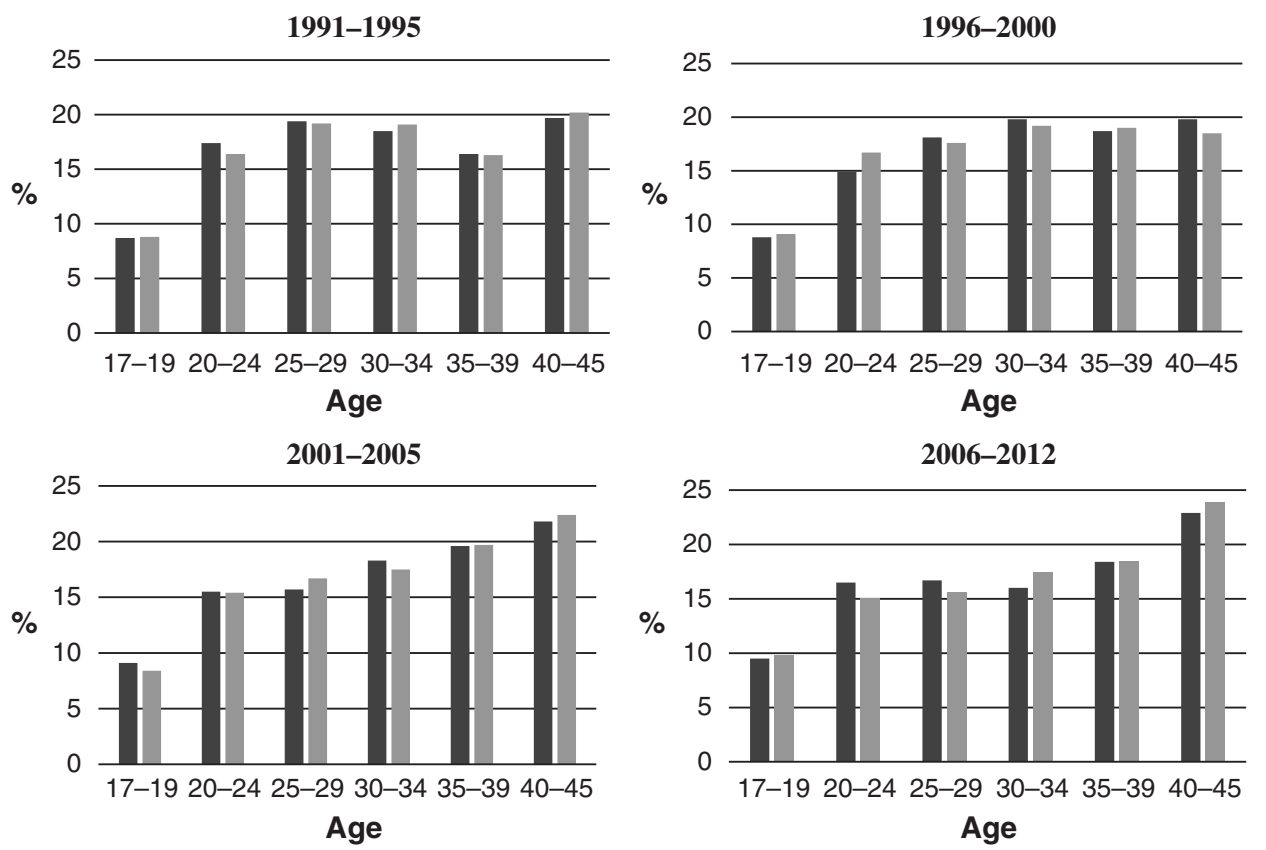

ONS BHPS

Sources: BHPS 1991-2009; UKHLS 2010-2014; ONS (2016). 
Figure A.2:

Trends in live births (all birth orders) by partnership status for women aged 20-45 in England and Wales, 1991-2012

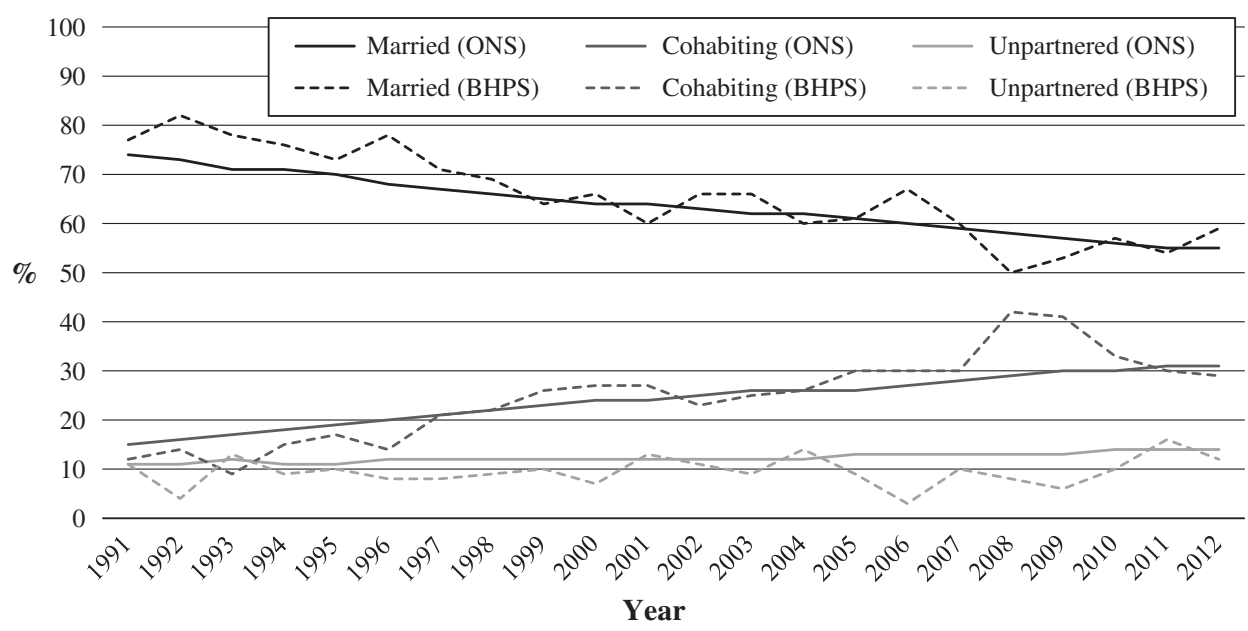

Sources: BHPS 1991-2009; UKHLS 2010-2014; ONS (2015).

Medium education (upper secondary qualifications) - includes A-Levels, Scottish Certificate of Sixth Year Studies, Higher School Certificate, Ordinary National Certificate/Diploma, BEC/TEC/BTEC, National/General Certificate or Diploma, O-Level grades A-C, GCSE grades A-C, CSE grade 1, Scottish O-Grades (pass or bands A-C or 1-3), School Certificate or Matric, Scottish Standard Grade Levels 1-3, and City \& Guilds Certificate.

High education (degree level and other higher qualifications) - First degree or higher, Higher National Certificate/Diploma, teaching qualifications, and nursing qualifications.

In order to check the comparability of the educational measure, we performed a cross-tabulation of individual qualifications in wave 18 of the BHPS and the second wave of UKHLS (see Table A.1). The cross-tabulation shows a very close match between the two surveys. Overall, $94 \%$ of respondents who were interviewed in both waves had the same level of education and $6 \%$ had a higher level of education in the 2010/11 survey than in the 2008 survey. The main reason for this increase is the accumulation of additional qualifications between the two waves. A negligible proportion of respondents had a lower level of education $(0.2 \%)$, which can be attributed to coding errors or incorrect reporting of qualifications. We therefore conclude that, on the whole, the comparability of the measures of educational attainment used in the two surveys is very high. 
Table A.1:

Cross-tabulation of educational attainment at wave 18 of the BHPS and at the 2nd wave of the UKHLS (sample sizes in parentheses)

\begin{tabular}{lllll}
\hline \multirow{2}{*}{$\begin{array}{l}\text { Education at } \\
\text { wave 18 BHPS }\end{array}$} & \multicolumn{4}{c}{ Education at wave 2 UKHLS } \\
\cline { 2 - 5 } & Medium & High & Total \\
\hline Low & $87 \%(1339)$ & $12 \%(189)$ & $1 \%(18)$ & $100 \%(1546)$ \\
Medium & $0 \%(8)$ & $95 \%(2564)$ & $5 \%(122)$ & $100 \%(2687)$ \\
High & $0 \%(1)$ & $0 \%(1)$ & $100 \%(1431)$ & $100 \%(1433)$ \\
Total & $24 \%(1348)$ & $48 \%(2754)$ & $28 \%(1571)$ & $100 \%(5666)$ \\
\hline
\end{tabular}

Sources: BHPS (1991-2009), UKHLS (2010-2014)

The distribution of educational qualifications for men and women from 1991 to 2012 is also presented in Table A.2. It shows that the share of individuals with higher education more than doubled, from $14 \%$ in 1991 to $30 \%$ in 2012 . The proportion of individuals with upper secondary education also increased, from 38\% in 1991 to $49 \%$ in 2012 . Meanwhile, the share of individuals with lower secondary education decreased, from $48 \%$ in 1991 to $21 \%$ in 2012 . The share of highly educated men was higher than the share of highly educated women until recent years, when women overtook men. 


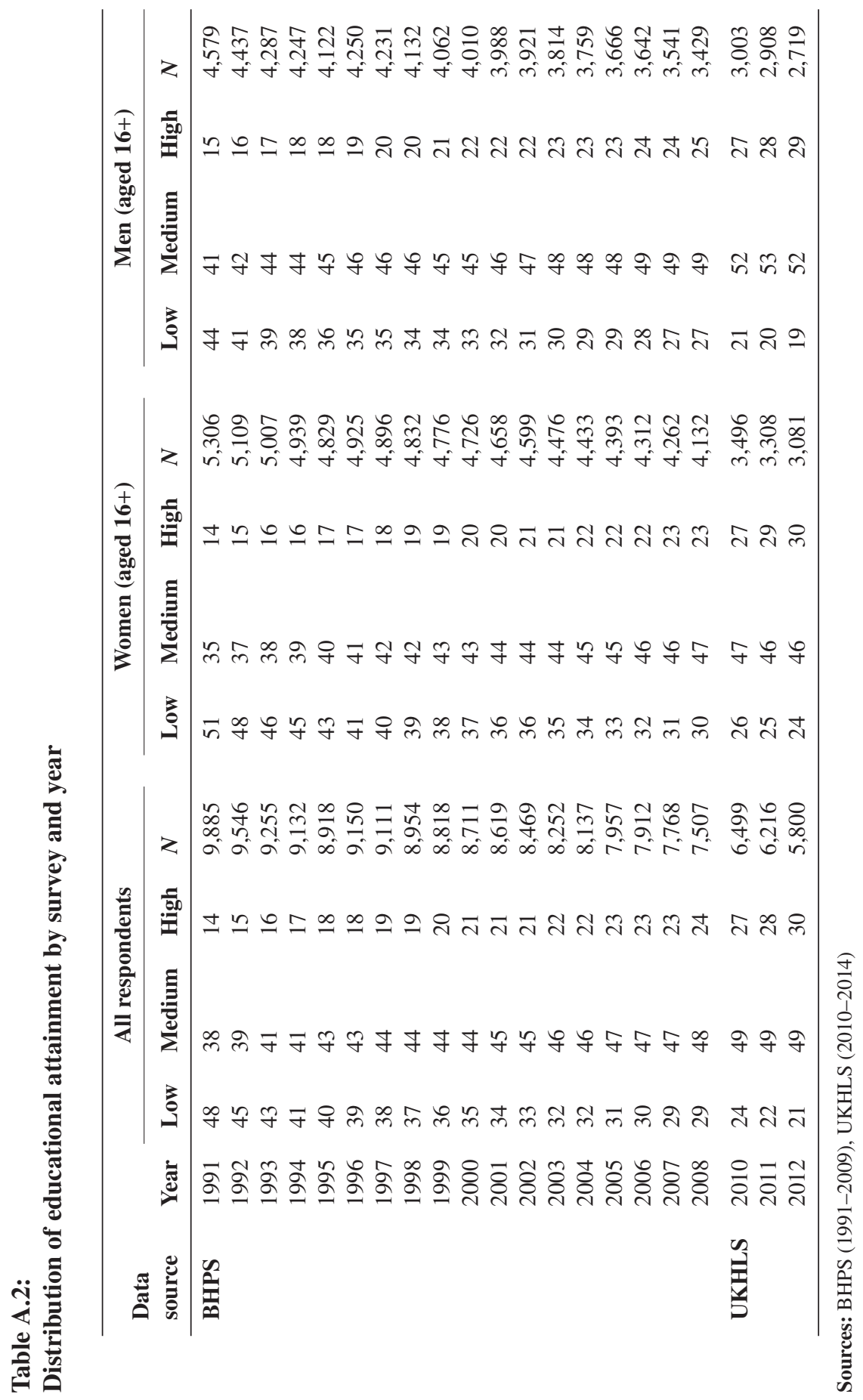


